\title{
Efeitos da educação formal,
}

\section{categorias ocupacionais e posição social}

Odaci Luiz Coradini*

Resumo: Este artigo apresenta resultados de um estudo sobre as relações entre o montante de rendimentos, a quantidade de escolarização e outros indicadores de posição social no Brasil. Em geral, as relações não lineares entre a quantidade de anos de estudo e o montante de rendimentos são atribuídos ao efeito do diploma, mas este estudo sustenta a hipótese de que, embora o efeito do diploma esteja quase sempre presente em algum grau, tem um peso mínimo nas diferenças de rendimentos. $\mathrm{O}$ aumento da rendimentos é negativo para diversas categorias do número de anos de estudo e o efeito positivo só é significativo nas faixas mais altas, sobretudo para aquelas com o maior número de anos. Conjuntamente com a quantidade de anos de estudo ou o grau de titulação escolar, são apresentados resultados da análise de outros indicadores de posição social, particularmente aqueles ligados à ocupação e suas relações com o montante de rendimentos.

Palavras-chave: retornos dos investimentos em educação; efeitos individuais da educação; categorias ocupacionais e posição social; educação e posição social, educação, ocupação e rendimentos.

\section{Revisão da literatura}

E ste artigo apresenta os resultados de um estudo sobre as relações entre educação e rendimentos e outros indicadores de posição social no Brasil. Estes indicadores de posição social incluem a ocupação e a posição na ocupação. Como estudo sociológico, explora um conjunto de indicadores que podem interagir com os efeitos da escolarização sobre a posição social. O artigo não objetiva demonstrar qualquer relação positiva entre o grau de educação formal e o montante de rendimentos. É claro que há algum efeito positivo em tal relação, até porque pelo menos parte dos investimentos educacionais individuais visa algum retorno econômico, enquanto outras modalidades de escolarização podem ser obrigatórias ou aponta principalmente para objetivos políticos, morais e culturais, ou motivações diferentes. De qualquer modo, a tese principal do artigo sustenta que as relações dos efeitos da educação formal no montante de rendimentos varia conforme a respectiva posição social. Portanto, mais do que as relações positivas entre a quantidade de escolarização e dos rendimentos, o foco principal aqui é a sua variação de acordo com os principais indicadores de posição social conforme as informações disponíveis, particularmente aquelas relativas à ocupação e à posição na ocupação e, em alguns dos bancos de dados, às origens sociais.

Pesquisas sobre os efeitos gerais do grau de escolarização e, em particular, sobre os retornos econômicos dos investimentos educacionais, têm sido frequentemente

\author{
* Doutor em \\ antropologia social \\ e professor da \\ Universidade Federal \\ do Rio Grande do Sul \\ (UFRGS).<coradini@ \\ ufrg.br>.
}


1. Evidentemente, as referências teóricas mais gerais continuam sendo as formulações de Becker (1967) e de Mincer (1974). Para um balanço geral da bibliografia internacional e os problemas e limites metodológicos nos estudos dos retornos da educação, ver Baudelot et alii (2004 104). voltadas para estabelecer as bases para a legitimação de causas politicamente constituídas. Psacharopoulos $(1985 ; 1994 ; 2008)$ e Psacharopoulos e Patrinos (1994) são as principais referências internacionais para este tipo de estudo. A maioria desses trabalhos enfoca estritamente as relações entre a quantidade de escolarização e o montante de rendimentos, além da eventual inclusão de variáveis ligadas à família, ao setor de trabalho, ao tipo de escola e a outros indicadores de qualidade da educação (ver particularmente Altonji \& Dunn, 1996; Patrinos, 1995; Björklund \& Kjellström, 2000; Alba-Ramirez \& Segundo, 1995; Liu, Hammitt \& Lin, 2000; Moffitt, 2007; Long, 2009). No Brasil, começando com o antigo trabalho de Langoni (1974), uma série de estudos econômicos dedicam-se a demonstrar os retornos dos investimentos em educação. Dentre esses trabalhos, aquele de um grupo de economistas norte-americanos (Lam \& Schoeni, 1993a e 1993b; Lam, 1992) destaca-se a partir de 1990. ${ }^{1}$ Estes estudos sobre as condições brasileiras, com base em pesquisas realizadas em outros países, concluem que os investimentos em educação têm um retorno maior para as populações mais pobres e para aqueles com menor grau de escolarização. Tais estudos ressaltam que esses retornos são mais elevados no Brasil do que nos Estados Unidos. No entanto, as discussões vão muito além do campo das ciências sociais e estão relacionadas a diferentes correntes da economia e aos usos de resultados desse tipo de pesquisa para fundamentar tomadas de posição frente a questões mais gerais. Por exemplo, em sua análise dos efeitos das relações familiares sobre retornos educacionais no Brasil, Lam e Schoeni (1993a: 738) argumentam que, embora os resultados obtidos fossem consistentes com o modelo do "estruturalismo" devido às imperfeições do mercado de trabalho e do papel dos vínculos familiares, mesmo assim, isso não impediria que fossem interpretados de acordo com a teoria do capital humano. Mais recentemente, Veloso et alii (2009) conduziram uma série de estudos nessa mesma linha. Poderíamos incluir também vários estudos de economistas, como Fernandes e Harita (2001). Apesar de não ser possível deter-se mais detalhadamente sobre o tema no presente artigo, nestes estudos dois pontos principais devem ser destacados: em primeiro lugar, como as pesquisas constatam, um alto retorno sobre investimentos em educação, um baixo grau de investimento é considerado como um "paradoxo". Ou seja, os alunos são tomados como agentes potenciais de investimentos financeiros. O segundo ponto a ser ressaltado para uma melhor compreensão deste quadro analítico é que embora as pesquisas levem em consideração os retornos médios sobre os investimentos em educação, não têm considerado as grandes diferenças de rendimentos relacionadas com o tipo e o grau de titulação escolar (ver particularmente Neri , 2009).

Em síntese, em termos estritamente econômicos, os estudos sobre este problema geralmente têm analisado as relações entre certos indicadores e destacado aqueles que representam a quantidade de escolarização. Geralmente, a quantidade de escolarização é medida em graus e em anos de estudo. Estes estudos também têm incluído 
o montante de rendimentos (do trabalho principal, dos demais trabalhos, de outras fontes) e, em alguns casos, a ocupação exercida, além de outras variáveis, com a constatação de fortes relações positivas entre investimentos em educação e seus retornos econômicos. Baudelot et alii (2004: 84 e 93) destacam que para os levantamentos mais recentes em âmbito mundial, em termos gerais e em média, o crescimento dos rendimentos individuais associado com um ano de estudo adicional é de 10\%,com variações substanciais. Em geral, esse impacto é mais forte para as populações mais pobres, com baixos níveis de escolarização.

Os estudos econômicos têm utilizado uma variedade de abordagens para esta questão. Porém, a teoria do capital humano, que define a educação como a aquisição de capacidades que afetam a produtividade do trabalho, é provavelmente a mais amplamente utilizada. No entanto, existem outras abordagens, incluindo a teoria da "triagem pela educação". Esta teoria é baseada na premissa de que as empresas não podem saber, a priori, o potencial produtivo dos potenciais empregados e, assim, usam o grau de educação como critério para comparar os candidatos (Baudelot et alii, 2004: 100-101).

Mesmo em alguns dos estudos citados, a quantidade de educação formal, seja medida pelo título mais alto obtido ou pelo número de anos de estudo, não mantém a mesma importância nas relações com o montante de rendimentos econômicos. Este fenômeno tem sido observado em uma variedade de contextos, como em países desenvolvidos, e tem sido chamado de "efeito pele de carneiro". A não linearidade destas relações ilustra as dificuldades metodológicas inerentes à mensuração dos efeitos da educação sobre os retornos econômicos (Baudelot et alii, 2004: 103). Ou seja, em determinados anos de estudo os resultados econômicos são mais elevados que outros, particularmente naqueles em que é sancionado o fim de um ciclo escolar ou ocorre a obtenção de um diploma. Isso estaria na base da não linearidade do acréscimo de rendimentos de acordo com a quantidade de anos de estudo. Segundo alguns estudos, esse efeito "pele de carneiro" pode ser responsável por até um quarto dos retornos da educação para alguns graus escolarização (Jaeger \& Page, 1996: 733).

O presente trabalho pressupõe que, para além dos efeitos restritos de algum condicionante específico, como aquele do diploma obtido, o problema consiste nas diferentes condições sociais associadas à realização da titulação escolar. Essas diferenças podem ser significativas mesmo entre pessoas com a mesma titulação escolar. Os mercados escolar e de trabalho não são monolíticos e títulos escolares se inserem em "múltiplos mercados" (Zelizer, 1992: 10) ou "mercados regulamentados" (Bourdieu \& Christin, 1990). O valor obtido pela titulação escolar está diretamente associado com a respectiva posição relativamente às estruturas de poder e de organização e de defesa de interesses (Bourdieu, 1989; 1984). 
2. Para um resumo comparativo das pesquisas sobre educação e outros indicadores, bem como a mobilidade social em diferentes países europeus, ver Breen, 2004. Sobre as diferenças da situação francesa em comparação com outros países e esquemas de classificação, ver particularmente Chauvel et alii (2002).

3. Para um resumo da "teoria liberal", ver Jackson, Goldthorpe \& Mills, 2002.
Embora o foco deste trabalho seja específico, envolve muitos problemas mais gerais que não podem ser abordados em detalhe aqui, mas que devem ser apontados. 0 primeiro é que a pesquisa sociológica que obteve o maior progresso na análise das relações entre escolarização, rendimentos econômicos e posição social, ao contrário de estudos econômicos, tem mantido posições teóricas que são relativamente independentes das demandas sociais e políticas. Uma das matrizes teóricas mais proeminentes na análise da interdependência entre os retornos dos investimentos em educação, o tipo de titulação escolar e a competência técnica e social bem como as condições necessárias para sua realização foi proposta por Bourdieu e seus seguidores e inspira mais resistência por razões morais, motivos políticos ou ontológicos do que em termos teóricos ou analíticos. Ou seja, a maior parte das discussões e tomadas de posição têm como base, de modo tácito ou explícito, as supostas implicações desse tipo de abordagem e de seus resultados analíticos em termos "práticos" ou de sentido. Isso abrange tanto questões relativas à adesão a valores como perspectivas e dramas próprios dos agentes diretamente envolvidos com os universos sociais em análise, particularmente aquele da escola. Embora alguns casos exemplares sejam mais explícitos, como aquele das polêmicas em torno dos significados da noção de "reprodução", trata-se de algo bem mais amplo e abrange as próprias concepções de ciências sociais. Para essa perspectiva teórica, os problemas analíticos centrais estão centrados nas relações entre as diferentes espécies de capitais ou os recursos envolvidos e as dimensões da estrutura do espaço de posições sociais e não apenas na formação escolar (ver, particularmente, Bourdieu, 1979; 1984; 1989; Bourdieu \& Saint Martin, 1997; Bourdieu \& Boltanski, 1975). Isto implica em vários problemas analíticos, nem todos podendo ser devidamente discutidos com o material empírico disponível. Consequentemente, este artigo pode parecer um tanto descritivo em alguns pontos, uma vez que a orientação adotada é a de evitar qualquer abordagem especulativa frente às limitações do material empírico.

Esta questão das condições de valorização da educação também é central nos trabaIhos de Goldthorpe e de sua equipe, embora com uma abordagem com outra base teórica. Em todo caso, também toma a multidimensionalidade da estrutura social como ponto de partida. O foco deste conjunto de pesquisas e de suas formulações conceituais tem sido o problema das relações entre escolarização, categorias ocupacionais e a mobilidade social. ${ }^{2}$ Esta abordagem resultou tanto em um esquema de classificação proposto para estabelecer os parâmetros nas relações entre ocupações com classes ou posição social (Erikson \& Goldthorpe, 1992) como um esquema de classificação para os graus escolares (Cassmin), tendo em vista comparações internacionais ( Müller, 2011; Breen \& Luijkx, 2004). O aspecto mais importante deste conjunto de pesquisas é ele que tem proporcionado uma base para a crítica do que é geralmente referido como "teoria liberal" ou as versões mais economicistas da teoria do capital humano. ${ }^{3}$ Embora uma discussão completa destes trabalhos esteja além do 
escopo deste artigo, há uma série de problemas não resolvidos nesses esquemas de classificação de ocupações e profissões em relação à classe ou à posição social. Essas questões incluem tanto problemas teóricos como epistemológicos, como as relações entre objetivismo e perspectivismo e problemas relacionados com a metodologia e as fontes de dados. Uma das principais questões no que tange às relações entre objetivismo e perspectivismo consiste nas dificuldades em distinguir entre classe como condição, posição e tomada de posição ou como formulação e aplicação dos princípios de classificação e de identidade (Bourdieu, 1979: 543-598). Essa ambiguidade faz com que seja difícil determinar se esses esquemas de classificação, de ocupações, entre outros, são o resultado de confrontos sociais e políticos, ou se, em sua formulação, as preocupações relacionadas com a execução de políticas governamentais (as "ciências de Estado") são impostas de modo mais estrito.

\section{Fontes de material e métodos}

As técnicas analíticas utilizadas neste trabalho foram adotadas com base nos objetivos gerais, que incluem a análise da diversidade e complexidade das relações entre escolarização, montante de rendimentos e posição social. A escolha foi também determinada pelos tipos de fontes e dados empíricos disponíveis. A aplicação destas técnicas analíticas está relacionada com o problema dos efeitos reversos ou da causalidade circular, que são particularmente fortes na questão em estudo. De acordo com Baudelot et alii (2004: 15-16), os efeitos do grau de escolarização nunca são "puros", porque interagem com outras variáveis, tais como riqueza, capital cultural, religião e comunidade específica. Assim, surgem problemas de causalidade circular, como na relação entre crescimento econômico e educação, e de endogeneidade, como na relação entre saúde e nível educacional. Além disso, muitos estudos têm examinado os efeitos "cívicos" da educação e adotam uma abordagem normativa e prescritiva, na qual os códigos da moral cívica são geralmente tomados como fundamento das ciências sociais (ver, entre outros, Brand, 2009; Dee, 2003). Por sua vez, estudos sociológicos, em especial aqueles em sociologia da educação, têm sido mais diretamente comprometidos com o "escola-centrismo", que confunde o objetivo da análise com a defesa da educação como valor moral (para um caso exemplar, no Brasil, ver Barbosa, 2009). Por outro lado, além desses problemas de causalidade circular e de endogeneidade, é necessário considerar as relações entre esses problemas metodológicos e seus respectivos fundamentos teóricos e conceituais. Este trabalho considera a causalidade estrutural e a multidimensionalidade nos usos dos títulos escolares e das classificações ocupacionais e profissionais, o que tem implicações para as técnicas de análise de interdependência e de dependência. ${ }^{4}$ Embora não seja possível expor a totalidade dos resultados, foram utilizadas diferentes técnicas de análise, tanto dirigidas ao exame da interdependência como da dependência entre variáveis, o que pode parecer metodologicamente ambíguo. No entanto, o objetivo é evitar transformar as opções

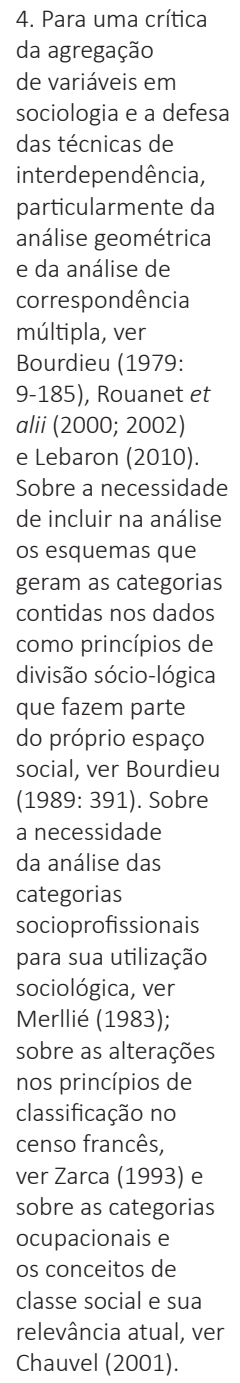

4. Para uma crítica a agregação sociologia e a defesa das técnicas de particularmente da análise geométrica e da análise de correspondência múltipla, ver 9-185), Rouanet et alii (2000; 2002 e Lebaron (2010) re a necessidade os esquemas geram as categoria contidas nos dados divisão sócio-lógica que fazem parte do próprio espaço social, ver Bourdieu a necessidade da análise das categorias socioprofissionais sociológica, ver Merllié (1983); sobre as alterações nos princípios de censo francê ver Zarca (1993) sobre as categorias upacionais e classe social e sua Chauvel (2001). 
5.Para uma discussão mais geral dos problemas de conceituação de causalidade em sociologia, ver Goldthorpe (2001).

6.Para os critérios de conversão dos cursos e séries em anos de estudo para as bases de dados usadas, ver IBGE (2002) e (2003).

\section{Como já} mencionado, os esquemas de classificação como o Cassmin (Müller, 2011) foram definidos como parte dos esforços para estabelecer comparações internacionais. No entanto, este tipo esquema não é aplicável para o presente trabalho, visto que os códigos utilizados na coleta dos dados são incompatíveis. técnicas, quando há problemas metodológicos que sem solução definitiva, em posição teórica. Por exemplo, quando comparadas as principais variáveis, o grau de interdependência é evidente. Quando é utilizada análise de regressão ou outras formas de análise baseada na dependência, é possível observar um certo grau de determinação. No entanto, embora não se pretenda negar a validade desses resultados, não se pode assumir que a causalidade foi comprovada experimentalmente. Em última análise, é a própria definição de causalidade que está em questão. Por exemplo, se for exigida como requerimento alguma sequência temporal de eventos (Hair et alii, 2009: 550), a noção de causalidade não se aplica. ${ }^{5}$ Da mesma forma, pode-se facilmente "provar" a ocorrência do aumento de rendimentos com a elevação do grau de escolarização, mas é igualmente possível mostrar que aqueles que alcançam níveis mais elevados de educação vêm de melhores condições econômicas.

Essas questões têm implicações diretas para o presente estudo, incluindo uma de suas variáveis centrais: a quantidade de escolarização medida por anos de estudo. Esta variável é medida em anos, em vez de graus o que, em geral, é visto como um indicador mais objetivo e mais fácil de comparar entre diferentes contextos. Para os dados do presente trabalho, a quantidade de anos de estudo não resulta de alguma pergunta apresentada ao entrevistado, sendo que a estimativa é feita com base no último curso e série concluídos. Este cálculo é feito pelo organismo responsável pela coleta das informações (IBGE). Os períodos de estudo que não resultam em aprovação certificada não são considerados para o cálculo dos anos de estudo. Portanto, os anos de estudo consideram a frequência escolar somente quando é oficialmente bem sucedida (o que não é socialmente simétrico) e não a frequência escolar como um todo. Assim, um dos principais problemas relativos aos estudos em suas relações com as demais variáveis é a falta de dados sobre o insucesso escolar (ou seja, quando o aluno não completa a série). Da mesma forma, as mudanças no tempo e na duração do ano escolar, como resultado da legislação estadual ou regional não são incluídos nos critérios. ${ }^{6}$

Além desses problemas de mensuração, a quantidade de anos de estudo consiste num indicador abstrato e genérico, particularmente no que diz respeito às diferentes funções e significados da educação e de seus usos sociais. Em geral, é pressuposta a equivalência geral entre os diferentes tipos de escolarização. Isso inclui aqueles cursos e títulos associados à regulação do mercado de trabalho e de prerrogativas profissionais, aqueles com formação para acumulação de capital social e detenção de posições de comando e tomadas de decisão, como busca de credencial (Collins, 1979) ou crédito cultural para recrutamento de líderes do grupo (Brown, 2001: 24-26), dentre tantos outros tipos, objetivos e interesses envolvidos. Assim, embora os valores sociais dos títulos escolares sejam diversos (Bourdieu, 1989; 1984), são tomados como equivalentes. $^{?}$ 
No que tange à variável central no trabalho - o montante de rendimentos -, o primeiro problema é a falta de um indicador complementar para o exame da posição social relativamente ao patrimônio econômico. Assim, é difícil distinguir entre rendimentos do trabalho ou daqueles decorrentes da posse de patrimônio econômico, exceto indiretamente. A melhor alternativa foi tomar o rendimento total de todas as fontes, não apenas os rendimentos do trabalho principal ou do conjunto dos trabalhos. Os dados da Pesquisa Nacional por Amostra de Domicílios (Pnad) são coletados a partir de informações sobre o rendimento mensal do trabalho principal, rendimentos mensais de todos os trabalhos e rendimentos mensais de todas as fontes, para indivíduos de 10 anos de idade ou mais. Além disso, também são coletados dados relativos aos rendimentos familiares, que não são relevantes para este trabalho. Os censos fornecem informações específicas sobre o rendimento bruto do trabalho principal, dos demais trabalhos e rendimento total. Visto que o principal interesse são as relações entre os anos de estudo e o montante de rendimentos conforme a posição social e considerando a falta de informações sobre o patrimônio econômico, a variável tomada como mais relevante é a do total de rendimentos de todas as fontes para as Pnad's e o rendimento total para os censos. Esse total de rendimentos foi dividido pelas horas de trabalho semanais para eliminar o efeito das diferenças de tempo de trabalho sobre o montante da rendimentos. ${ }^{8}$ Foi empregado o resultado desta divisão dos rendimentos totais pelas horas de trabalho semanais nos testes estatísticos, com algumas exceções que são expressamente indicadas. Os valores são sempre apresentados em reais do período em consideração. Portanto, os valores expressos nos resultados dos testes estatísticos representam as diferenças quantitativas desse indicador que resulta da divisão do total dos rendimentos pela quantidade de horas semanais trabalhadas, relativamente ao tipo de teste e de variável em exame, em moeda brasileira da época. A alternativa de converter os valores em dólares norte-americanos foi posta em prática, mas posteriormente rejeitada devido à impossibilidade de comparações históricas em períodos mais significativos. Além disso, ocorre perda de precisão ao converter moedas em períodos com inflação elevada e os resultados para cada base de dados tomados separadamente são muito semelhantes. Também ocorrem problemas nas definições das categorias de classificação e agrupamento da ocupação e da posição na ocupação. Os esquemas para a classificação das ocupações passam por mudanças constantes e rápidas que impedem a formação de uma série temporal mais ampla. Porém, o problema geral não decorre apenas dessas mudanças, mas do caráter compósito e ambivalente dos princípios e critérios de classificação e agrupamento. No entanto, é importante salientar que, por um lado, tais problemas de fontes podem decorrer tanto das alterações periódicas como das ambivalências das categorias utilizadas. Por outro lado, esses problemas também podem ter origem mais ampla, na medida em que tanto os antigos critérios de classificação das ocupações relativamente específicos para cada país como os esquemas que tendem a impor-se como universais (no caso em pauta, particularmente aquele com base na Internatio-
8. Esta técnica foi inspirada no trabalho de Lam e Schoeni (1993a: 720). No entanto, este trabalho utiliza o resultado da divisão dos rendimentos mensais em todos os trabalhos e não apenas do trabalho principal, sobre o número de horas trabalhadas por semana. Foram comparados os resultados tomando o rendimento do trabalho principal, de todos os trabalhos e de todas as fontes, mas apesar das evidentes diferenças de valores, as posições relativas não sofrem grandes alterações. 
9. Sobre o caráter particularístico do capital de relações sociais em Bourdieu em confronto com as versões com origens em Coleman, ver Coradini (2010b).

10. Para maiores detalhes empíricos, ver IBGE (2010) e a documentação e notas técnicas que acompanham a base de dados usada. nal Standard Classification of Occupations (Isco-88) não tem na posição social seu foco e princípios de classificação. Este constitui precisamente um dos principais pontos de discussão atuais (Chauvel, 2001; 2002; Erikson \& Goldthorpe, 1992; Bergman \& Joye, 2005) e, no que tange ao Brasil, originou um estudo específico em curso sobre os problemas das relações entre esquemas de classificação estatística e estrutura social. Não obstante, além dos problemas relacionados às categorias de classificação em seu sentido objetivista e as filosofias sociais subjacentes aos esquemas, em termos mais gerais as dificuldades também decorrem da existência de recursos que poderiam ter grande importância e efeitos em termos de posição social e mais especificamente quanto ao valor do grau de escolarização, mas cujos princípios são menos legítimos e publicamente declarados. É o caso, por exemplo, de mecanismos de transmissão do patrimônio cultural, das relações entre o consumo cultural e os estilos de vida e particularmente do capital de relações sociais. ${ }^{9}$

Como Coradini (2010) apontou, as classificações que têm sido utilizadas com este tipo de dados resultam da confluência de vários princípios distintos. Alguns estão relacionados com posições de propriedade e de comando. Como tal, muitas categorias ocupacionais, mais que "ocupação" ou "profissão", são equivalentes a alguma posição social dominante, como é o caso, por exemplo, das categorias dos "proprietários", "empregadores", dentre outras. Algumas das categorias estão mais diretamente associadas com as classificações escolares e suas prerrogativas e outras se originam da apropriação de categorias que são forjadas em lutas sociais ou por suas relações com a representação sindical ou corporativa. Além disso, o princípio da perspectiva setorial tem um peso decisivo no conjunto dos esquemas de classificação das ocupações. Em síntese, há uma matriz de classificações cujo princípio básico está centrada na divisão (social e técnica) do trabalho e na suposta "competência" necessária para o exercício de determinada ocupação. Uma das principais consequências dessa matriz é que a classificação de ocupações está mesclada com outro esquema, que classifica ocupações por "atividades". Aparentemente, este carácter setorial da classificação ocupacional era muito mais forte nas décadas passadas, mas com a influência crescente dos esquemas internacionais como a Isco-88, esse caráter setorial continua em novas modalidades. De qualquer modo, mesmo no período mais recente, este caráter setorialista está associado com a divisão técnica e social do trabalho, apesar de a "competência" também ser decisiva como princípio geral. ${ }^{10}$ As organizações responsáveis pela coleta de tais informações no Brasil adotam o Código Brasileiro Ocupações (CBO), mas com diferenças em relação aos esquemas de classificação aplicados em outros países. A adoção de esquemas de classificação que têm uma base mais sociológica, como o proposto por Erickson e Goldthorpe (1992), apresenta muitos desafios técnicos, mesmo quando são adaptados para o uso em situações diferentes (Breen, 2004), devido a problemas com a forma como a informação é recolhida. Em todo caso, o problema geral envolve as dificuldades de classificação, que mantêm uma dimensão técnica, 
mas também estão relacionadas com os interesses envolvidos nos processos sociais e políticos pelos quais os códigos de classificação são formulados. Isso se relaciona com o problema mais geral dos interesses e os esquemas de avaliação daqueles que coletam, classificam, armazenam e difundem as informações estatísticas (Merllié, 1983; Chauvel et alii, 2002).

Grupos ocupacionais representam agrupamentos de categorias com base em diferentes princípios e os principais efeitos negativos disso são as ambivalências e contradições internas. Um caso típico do processo de agrupamento com base em princípios diferentes ocorre quando determinado agrupamento está baseado em algum "setor" ou "ramo" de atividade que abrange categorias completamente distintas e distantes quanto à posição social ou às relações de trabalho. Essa situação ocorre, por exemplo, quando os "trabalhadores na agricultura" abrangem proprietários e técnicos com diferentes níveis de ensino num mesmo agrupamento. Em graus diversos todos os agrupamentos contêm este tipo de ambivalência.

O principal problema com a utilização da posição na ocupação como variável pela qual, em princípio, se baseiam as relações de trabalho, decorre da generalidade excessiva das categorias. Além disso, muitas destas categorias são instáveis como indicação de posição social e frequentemente mudam. No entanto, como demostrado pelos resultados apresentados, mesmo assim a posição na ocupação pode constituir um bom complemento para as categorias ocupacionais. Sua principal vantagem é a de destacar uma das principais dimensões da divisão do trabalho, isto é, o seu controle, o que é proposto inclusive por esquemas como aquele enunciado por Erickson e Goldthorpe (1992), apesar da amplitude excessivamente ampla, como já mencionado.

Assim, um dos efeitos mais diretos desses problemas para este trabalho é que os grupos ocupacionais e por posição na ocupação, que estão fortemente associados com os rendimentos e os anos de estudo, variam de acordo com a base de dados em uso, pois os critérios de classificação mudam. Outro efeito direto está na origem da causalidade circular nas relações entre grupos ocupacionais, anos de estudo e montante de rendimentos. Visto que os esquemas de classificação escolar estão presentes nas classificações ocupacionais e profissionais, as associações entre categorias e agrupamentos ocupacionais, escolarização e montante de rendimentos, à primeira vista, podem ser tomadas como relações causais. No entanto, essas associações podem consistir no resultado das origens comuns dos esquemas de classificação, num exemplo típico de causalidade reversa mencionada no início deste item. De qualquer modo, é importante destacar que todos estes problemas relativos à qualidade dos dados empíricos estão mais diretamente associados às possibilidades de maior ou menor grau de especificação e para comparações em séries históricas. Nenhum desses problemas 
11. Os microdados do censo de 2010 ainda não estavam disponíveis no final do trabalho de análise.

12. Sobre as diferenças das técnicas de análise de interdependência e de dependência ver, particularmente, Hair Jr. et alii (2009). abrange a confiabilidade das tendências verificadas, embora muitos deles permaneçam em um grau relativamente genérico.

As fontes mais diretamente utilizadas são constituídas pelas Pesquisa Nacional por Amostra de Domicílios (Pnad) e pelos censos do IBGE disponíveis em microdados. Foram exploradas todas as bases em microdados, mas algumas foram utilizadas para estudos mais sistemáticos. Estes estudos incluem a Pnad de 2006, por se tratar de uma das mais recentes então disponíveis e das Pnad's de 1988 e de 1996 porque incluem indicadores de origens sociais, além de servirem como expansão e reforço de evidências para a Pnad de 2006. A Pnad de 1988 também inclui indicadores mais detalhados relacionados com engajamento associativo, sindical e político, além das origens sociais. Finalmente, o censo de 2000 foi incluído neste estudo sistemático porque contém informações sobre os tipos de curso concluído e o número de anos de estudo, além de servir como expansão e reforço de prova. Após a conclusão da análise destas bases de dados, os microdados da Pnad para 2009 tornaram-se disponíveis e foi então realizada uma exploração mais sistemática também da mesma. No entanto, este artigo apresenta apenas os resultados desta análise posterior que diferem significativamente das anteriores (por exemplo, no caso da análise de regressão das principais variáveis). ${ }^{11}$ Porém, apesar da exploração do conjunto dessas fontes - que inclui os censos de 1970 a 2000 e as Pnad's de 1976 a 2009 -, o presente artigo apresenta apenas alguns dos resultados e por uma questão de disponibilidade de espaço, a exposição está centrada nas Pnad's de 1996, 1998, 2006 e 2009. Essa exposição centrada nessas fontes e a disposição das tabelas anexas, no entanto, não equivale a algum recorte empírico delimitado nas mesmas. Trata-se apenas de tomar alguns casos exemplares para maior detalhamento.

Algumas técnicas estatísticas visam demonstrar o grau de interdependência ${ }^{12}$ dos anos de estudo, o montante de rendimentos com outras variáveis e dimensões. Foram utilizados testes de correspondência múltipla, correlações e diagnóstico de multilinearidade, entre outros, para analisar os graus de associação entre variáveis, nem sempre incluídas nos modelos de regressão. No entanto, um segundo conjunto de técnicas tem como objetivo elaborar modelos de regressão e incluem não apenas os anos de estudo e o montante de rendimentos, que são comuns na literatura econômica, mas também variáveis relacionadas a outras dimensões. Entre essas variáveis, este trabalho incluiu grupos ocupacionais e os grupos por posição na ocupação como variáveis independentes, além de anos de estudo. Foi utilizado o montante de rendimentos como variável dependente em todas as bases de dados usadas. Além deste modelo geral, as variáveis relacionadas com origens sociais foram incluídas em um segundo modelo para os bancos de dados das Pnad's de 1996 e de 1988. No caso do censo de 2000, foi examinado o tipo do último curso concluído e o destino ocupacional. Para todos os modelos com estas variáveis, foram utilizados testes de regressão 
linear, com variáveis binárias para os parâmetros categoriais, além de testes de regressão multinomial. Por último, foi realizada uma análise de variância (Anova) para explorar os subgrupos formados ao tomar separadamente as categorias de variáveis, tais como as faixas de anos de estudo, da ocupação e da posição na ocupação. Esta técnica permite um maior grau de especificação para as relações entre anos de estudo e as variações de rendimentos em todos os subgrupos, explorados separadamente e não mais em conjunto.

Como já mencionado, embora não seja possível expor a totalidade dos resultados com diferentes técnicas de análise, deve ser destacado o grau de interdependência entre os anos de estudo ou outros indicadores da quantidade de escolarização, a posição social e o montante de rendimentos devido ao problema da causalidade circular. Das diferentes técnicas correntes, a mais adequada para o tipo de dados disponíveis é a análise de correspondência múltipla. Tal como acontece com outras técnicas para testar a interdependência entre variáveis e, mais especificamente a análise fatorial, esta técnica não examina os efeitos de uma ou mais variáveis sobre outras, como o montante de rendimentos, mas a interdependência entre o conjunto de variáveis ativas. Assim, é possível aferir o grau em que cada variável contribui para as estruturas subjacentes à base de dados. Este método inclui o peso das variáveis em relação à quantidade de anos de estudo e o montante de rendimentos. Como observado acima, embora, à primeira vista, esta utilização simultânea de técnicas que analisam a interdependência (análise fatorial) e a dependência (regressão) pode parecer ambígua, esta opção pretende mostrar as limitações do instrumental disponível. Além disso, esta utilização simultânea de diferentes técnicas evita tomar as opções técnicas, cujos problemas não foram definitivamente solucionados, como se fossem uma abordagem única.

Os testes de regressão analisam o grau de associação entre a quantidade de anos de estudo, o montante de rendimentos e outros indicadores, mas também evidenciam a não linearidade dessas relações. Como já mencionado, em geral os estudos sobre os retornos de investimentos na educação, além da constatação da associação positiva entre quantidade de escolarização e montante de rendimentos, operam através de valores médios gerais (ver, particularmente, os trabalhos já mencionados no primeiro item,em especial Psacharopoulos, 1994; 2008; Psacharopoulos \& Patrinos, 1994; e, para o Brasil, Neri, 2009). Como o problema em pauta não se limita à existência ou à quantidade de retorno dos investimentos em educação, mas abrange ainda as condições sociais e as lógicas de ação envolvidas neste tipo de investimento e de retorno, as variações de tais retornos são mais importantes. Uma das principais hipóteses deste trabalho é a de que as variações nos retornos dos investimentos em educação ou o aumento dos rendimentos para cada ano adicional de estudo pode ir muito além do "efeito pele de carneiro" decorrente da obtenção do diploma. De acordo com Bau- 
delot et alii (2004: 103), este efeito pode apoiar a teoria da "triagem pela educação", em detrimento daquela do capital humano. De acordo com Jaeger e Page (1996), nos Estados Unidos, o "efeito pele de carneiro" varia muito "de acordo com anos de estudo e oscila entre $15 \%$ e $50 \%$ da variação total", conforme o nível de ensino, a "raça" e a divisão por sexo. No entanto, estes autores são "relutantes para interpretar" estes resultados "puramente como o efeito causal do diploma recebido sobre o salário" (Jaeger \& Page, 1996: 739). No presente trabalho - como os resultados apresentados adiante indicam - o efeito diploma está quase sempre presente em certa medida para a Pnad 2006 e também para todos os demais bancos de dados explorados. No entanto, devido à alta e sistemática não linearidade entre os anos de estudo e o montante de rendimentos e à forte concentração dos retornos entre as faixas mais elevadas, o efeito diploma tem um peso mínimo na explicação das diferenças de rendimentos.

\section{Alguns resultados do exame do material empírico}

Como já mencionado, o trabalho do qual foi extraído esse artigo utiliza diferentes técnicas, seja para exploração geral das fontes ou para o exame da interdependência entre categorias de variáveis, como os testes de correspondência múltipla. Porém, da mesma forma que a maioria dos estudos sobre os efeitos da educação, este trabalho também utilizou testes de regressão linear e regressão multinomial para examinar as relações das variáveis independentes com o montante de rendimentos. Para os testes de regressão linear as variáveis categóricas foram dicotomizadas. Para todas as bases de dados foi elaborado um primeiro modelo geral que inclui os anos de estudo, a ocupação e a posição na ocupação como variáveis independentes e o rendimento total de todas as fontes sobre a quantidade de horas trabalhadas semanalmente, como a variável dependente. Um segundo modelo inclui também variáveis independentes que são específicas para algumas bases de dados, como o último curso concluído para o censo de 2000 e a ocupação e o grau de escolarização dos pais, disponíveis nas Pnad's de 1996 e de 1988.

Em termos gerais, tanto para Pnad's de 2006 (Tabela 2 no anexo) como para os demais testes desse tipo, a intensidade das associações é relativamente alta, embora para a Pnad 2006 em menor grau do que na maior parte das demais bases de dados. Quando analisada cada variável (dicotomizada) em relação ao montante de rendimentos, um dos graus mais fortes de associação ocorre com os anos de estudo ( $R$ de 0,278 e $R^{2}$ de 0,077$)$. No entanto, neste caso da Pnad 2006, outras variáveis têm um grau de associação que supera aquele dos anos de estudo. Isso ocorre para a ocupação em oito agrupamentos ( $R$ de 0,302 e $R^{2}$ de 0,091). A posição na ocupação tem o mesmo grau de associação com o montante de rendimentos que os anos de estudo ( $R$ de 0,278 e $\mathrm{R}^{2}$ de 0,077 ). Ao incluir somente as categorias destas três variáveis como independentes e manter o montante de rendimentos sobre o total de horas de trabalho semanais 
como variável dependente, o modelo apresenta graus relativamente elevados de associação (R para o modelo final de 0,359 e $R^{2}$ de 0,129$) \cdot{ }^{13}$

Em termos gerais, tanto para a Pnad 2006 como para os demais testes deste tipo, os resultados para os anos de estudo demostram os efeitos dos indicadores de posição social, como ocupação e posição na ocupação, nos anos de estudo. Assim, a posição social, neste caso, é reduzida à categoria ocupacional na divisão do trabalho e às relações de trabalho expressas na posição na ocupação. Estes são, obviamente, indicadores extremamente genéricos e parciais de posição social, mas é o máximo possível de ser obtido nos esquemas de classificação das fontes. De acordo com a definição de uma das principais posições teóricas que tem a posição social como conceito básico (Bourdieu, 1989: 375-385), os fundamentos da posição social assentam-se no montante e na estrutura de capitais, sendo, portanto, multidimensional. Conforme outra das principais posições teóricas (Erikson \& Goldthorpe, 1992; Bergman \& Joye, 2005: 8-13), a própria definição de ocupação em suas relações com a estrutura social contempla as dimensões como as transformações na forma de recursos econômicos e organização do trabalho, na divisão social e setorização do trabalho, dos rendimentos e das condições de acesso ao emprego, das modalidades de contratos e de controle do trabalho, entre outras. De qualquer modo, apesar das limitações das fontes relativamente à multidimensionalidade da posição social, os resultados são muito significativos. É importante ressaltar que, devido aos critérios antes mencionados para o cálculo dos anos de estudo, são excluídos aqueles sem a aprovação, abrangendo apenas a frequência escolar bem sucedida e com certificação. Se a frequência escolar sem a aprovação final fosse incluída, certamente os resultados seriam ainda mais contundentes. O mesmo ocorreria no caso de haver qualquer indicador de qualidade da educação.

No modelo final geral de regressão para a Pnad 2006 (Tabela 2), a maior diferença de rendimentos, conforme a quantidade de estudo, é mais de quatro centenas de vezes maior do que a base (medida em reais brasileiros). Essa diferença de rendimentos ocorre entre aqueles com quinze anos ou mais de estudo $(43,74)$ e a faixa de rendimentos mais baixa $(0,11)$, que corresponde aos que têm apenas um ano de estudo. Portanto, as variações do montante de rendimentos de acordo com anos de estudo são muito fortes neste teste de regressão linear. Outra tendência, que se repete com pequenas variações nos testes com as demais bases de dados, é que a elevação dos rendimentos, conforme os anos de estudo, é significativa apenas nas faixas mais altas. No entanto, simultaneamente com as variações muito fortes, formam-se alguns patamares em todas as bases de dados, também com variações internas. O maior desses patamares abrange aproximadamente a faixa de onze ou doze a quinze anos de estudo ou mais. A seguir, um outro patamar é formado em torno da faixa de oito ou nove a onze ou doze anos, com valores muito abaixo do anterior, mas também muito acima do extremo inferior,
13. A coluna dos coeficientes estimados (Unstandardized coefficients) das tabelas do Anexo expõe o resumo dos resultados de alguns desses testes de regressão linear, para as Pnad's de 1996, 2006 e 2009. Como já mencionado, em todas essas tabelas o respectivo teste tem como variável dependente o rendimento de todas as fontes sobre o total de horas trabalhadas semanalmente. Portanto, nesses coeficientes são expressas as diferenças quanto ao montante de rendimentos ponderado pela quantidade de horas trabalhadas relativamente a cada categoria das variáveis independentes (em moeda brasileira da época) Especificamente para a Pnad de 2006 (Tabela 2) as variáveis independentes consistem nos anos de estudo, na ocupação em oito agrupamentos e na posição na ocupação em seis agrupamentos. Visto que esses coeficientes expressam as relações e o grau de "determinação" das variáveis independentes sobre o montante de rendimentos numa determinada estrutura do conjunto que forma 
o respectivo modelo, o valor absoluto interessa menos que as diferenças relativamente a cada categoria das variáveis independentes. Esse valor é expresso em reais da época, uma vez que a conversão em dólares, como já mencionado, não resultou em melhorias significativas. também com fortes variações internas. Finalmente, ocorre outro patamar no extremo inferior, com valores muito mais baixos do que os demais e com variações internas ainda mais fortes. Partindo de valores muito baixos (0,11 para aqueles com um ano de estudo e valor constante de 2,41 para o modelo), o montante de rendimentos aumenta em mais de dez vezes para a faixa de dez anos de estudo (1,23). A partir dessa faixa são observados aumentos cada vez mais fortes e bruscos, com seu auge na penúltima faixa, de quatorze anos de estudo $(13,17)$ e a mais alta, com quinze anos de estudo ou mais $(43,74)$. O montante de rendimentos mais do que triplica entre estas duas faixas. Este resultado pode, em parte, ser atribuído ao fato de a última faixa incluir todos os níveis de ensino acima de quatorze anos. Portanto, existe um evidente efeito de sobreposição nos dados disponíveis, mas que abrange uma pequena proporção do universo. Também é constatado um aumento relativamente forte em rendimentos para aqueles com onze anos de estudo (15,6\%), com diminuição subsequentemente para 1,3\% para aqueles com doze anos, 1,0\% para aqueles com treze anos e 1,1\% para aqueles com quatorze anos. Em contrapartida, há um aumento para 5,1\% para aqueles com quinze anos ou mais de estudo. Apesar de algumas variações, outra tendência que se repete nas demais bases de dados e também nesse teste é a não linearidade das relações entre os anos de estudo e o montante de rendimentos. Em parte, esta constatação pode ser atribuída ao efeito diploma ou ao efeito "pele de carneiro", que, conforme a literatura discutida no primeiro item, em alguns contextos pode ser responsável por até a metade do acréscimo nos rendimentos. No caso em pauta, esse efeito é indicado pelos pequenos aumentos para as faixas que coincidem com a recepção de um diploma, com aquela com quatro, oito e onze ou doze anos de estudo. Porém, o peso desse efeito diploma é muito reduzido em relação à não linearidade das relações e do seu crescimento acelerado nas faixas mais altas de anos de estudo.

Com relação aos grupos ocupacionais, observam-se variações substanciais no modelo de regressão linear para a Pnad 2006, embora sejam menores que aquelas observadas nos anos de estudo. O agrupamento no extremo superior, os profissionais das ciências e das artes $(-1,40)$ apresenta um montante de rendimentos 18 vezes maior do que a categoria do extremo inferior (trabalhadores e produtores agrícolas (com $-25,64)$. No polo dos rendimentos mais elevados, apenas os do agrupamento dos dirigentes em geral se situam numa posição próxima daquela dos profissionais das ciências e das artes, enquanto os técnicos de nível médio e professores de ensino médio e aqueles em ocupações mal definidas (uma categoria utilizada pelo IBGE para aquelas ocupações que não se enquadram no respectivo esquema de classificação) e militares têm um rendimento intermediário. Embora não possa ser detalhado aqui, o agrupamento dos administradores, devido aos critérios de definição e classificação centrados na suposta "competência" necessária para cada ocupação, apesar de esta designação destacar o caráter "gerencial" do conjunto de categorias incluídas no agrupamento, contempla categorias mais diretamente centradas na detenção de capital 
econômico. Tal é o caso, por exemplo, dos "empregadores". No polo oposto, além dos trabalhadores (e produtores) agrícolas, estão os trabalhadores de serviço, já próximos do extremo mais baixo, que também inclui os trabalhadores de serviços administrativos e trabalhadores industriais.

No modelo de regressão linear para a Pnad 2006, os grupos relacionados com a posição na ocupação apresentaram variações menores. A diferença entre a categoria do topo, empregadores $(76,79)$ e do extremo inferior ou a categoria dos não remunerados $(30,97)$, é de menos de duas vezes e meia, visto que os resultados deste modelo dependem das interações com as demais variáveis. Ao incluir apenas as categorias de posição na ocupação no modelo, os resultados são completamente diferentes. A diferença entre a faixa de rendimentos superior (empregadores) e a faixa de rendimentos inferior (trabalhadores não remunerados) passa de 12 vezes. De modo semelhante aos resultados de todas as demais bases de dados, esta dimensão das relações de trabalho demostrada pela posição na ocupação e em particular na situação extrema superior dos empregadores consiste numa das mais fortes indicações do peso da posição social no valor da titulação escolar. Ou seja, estatisticamente nem os empregadores nem as demais categorias são definidas por critérios escolares, mas ao mesmo tempo, sua posição social tem efeitos muito fortes nos significados da escolarização. Em todo caso, no extremo superior do montante de rendimentos os empregadores destacam-se, onde também se situam os trabalhadores na produção ou construção para o próprio consumo ou utilização, os funcionários públicos estatutários e militares e os por conta própria. No polo oposto, além dos não remunerados, destacam-se os empregados sem carteira assinada, empregados com carteira assinada e empregados domésticos (com ou sem carteira assinada), em síntese, com posição social mais baixa ou grau de inserção no mercado mais precário.

Como já mencionado, os microdados da Pnad 2009 foram disponibilizados somente depois de a análise das demais bases de dados estar concluída. Os resultados para a maioria das análises são muito semelhantes. Sua inclusão justifica-se como expansão da evidência com dados mais recentes, mas não tem qualquer objetivo de comparar diferentes períodos, uma vez que isso implica em problemas técnicos, como já mencionado. No entanto, na análise de regressão das variáveis principais - incluindo os anos de estudo, ocupação e posição na ocupação como as variáveis independentes e o montante de rendimentos como dependente - foi constatado um grau muito maior de correlação que para a Pnad 2006. Esta diferença nos resultados entre estas bases de dados por incluir informações mais recentes, indica que os resultados para 2009 merecem a exposição de alguns pontos. Não apenas o grau de correlação entre as variáveis é muito mais elevado (com um $R$ de 0,528 e um $R^{2}$ de 0,279 ), como a não linearidade do montante dos rendimentos também é muito alta (Tabela 1). Como nas demais bases de dados, os maiores rendimentos são obtidos por aqueles com quinze 
14. O grupo ocupacional dos profissionais das ciências e das artes e a posição na ocupação dos empregados foram excluídos desta análise devido ao alto grau de multicolinearidade. ou mais anos de estudo (71,80, com um valor de 71,51 para o indicador obtido da divisão do total dos rendimentos de todas as fontes pelo número de horas trabalhadas por semana). A segunda faixa mais alta é dos que têm doze anos de estudo, mas com um valor bem abaixo daqueles com quinze anos ou mais $(51,72)$, seguidos por aqueles com quatorze anos de estudo. Todas as demais faixas estão muito abaixo, com as faixas intermediárias de rendimentos se situando nos onze anos $(24,81)$, seis anos $(20,64)$, nove anos $(15,35)$, dez anos $(14,82)$, sete anos $(10,68)$, quatro anos $(8,24)$, três anos $(6,22)$ e treze anos $(6,0)$. Finalmente, no extremo inferior da escala de rendimentos, estão as categorias com valores insignificantes de rendimentos e os com cinco anos de estudo $(2,7)$, oito anos $(1,84)$, dois anos $(0,45)$ e um ano $(-0,09)$. Estes dois últimos grupos têm menos correlações significativas.

Ao examinar as relações entre a categoria ocupacional, os anos de estudo e o montante de rendimentos para a Pnad de 2009, a única categoria com um montante de rendimentos positivo significativo é a dos administradores gerais $(19,73)$, o que, novamente, ressalta o efeito da posição social nessas relações. Aqueles com ocupações mal definidas (predominantemente militares) mantêm uma posição bem abaixo, mas ainda com valores positivos $(4,53)$. Todos os demais agrupamentos situam-se no extremo oposto, com valores negativos muito semelhantes, variando de $-57,52$ para os trabalhadores de serviços a -60,52 para técnicos de nível médio).

Os resultados de análise de regressão para a posição na ocupação obtidos para a Pnad 2009 são muito semelhantes aos das demais bases de dados, mas com um grau muito mais elevado de correlação entre a posição social, indicada pela posição na ocupação, a ocupação, os anos de estudo e o montante de rendimentos. Neste modelo, a única categoria com um valor positivo é a dos empregadores $(114,65)$. Todas as demais posições na ocupação situam-se no extremo oposto, com valores semelhantes, variando dos empregados sem carteira assinada, com um valor de -6,93 a funcionários públicos estatutários e militares em geral, com um valor de $-17,44 .{ }^{14}$

A base de dados do censo de 2000 (o censo 2010 ainda não estava disponível em microdados no momento da pesquisa) foi incluída por duas razões principais. Em primeiro lugar, porque esta base de dados contém uma amostra muito mais ampla do que as Pnad's. A segunda razão é a disponibilidade de outra informação relativa à educação, com a especificação do curso concluído. Quanto ao uso dessa fonte como a expansão de prova, também para o censo de 2000, o modelo de regressão linear inclui o montante de rendimentos sobre o total de horas trabalhadas como variável dependente e as categorias dicotomizadas dos anos de estudo, grupos ocupacionais e de posição na ocupação como as variáveis independentes (cuja tabela, por uma questão de espaço, não está incluída no anexo). Os resultados indicam para tendências semelhantes às já constatadas, mas muito mais contundentes. As variações no 
montante de rendimentos conforme os anos de estudo vão de 0,16 (com um valor constante de 17,73 ) para aqueles com um ano de estudo a 73,49 para aqueles com dezessete anos de estudo ou mais. Isso representa uma diferença de 110 vezes no montante de rendimentos.

Deve também ser destacado que, também neste caso, as relações entre anos de estudo e rendimento não são lineares. Além disso, esta não linearidade é muito maior do que o efeito diploma (particularmente nas faixas com quatro, oito e onze anos de estudo). Como nas demais bases de dados, nessa relativa ao censo de 2000 ocorre uma intensificação nas relações positivas entre anos de estudo e o montante de rendimentos somente nas faixas mais altas, particularmente naquelas com mais de onze anos de estudo.

Além disso, no que tange aos grupos ocupacionais, as variações no montante de rendimentos são muito fortes. A diferença entre o extremo inferior (-15,21, particularmente trabalhadores agropecuários, florestais e da caça e pesca) e o extremo superior $(3,02)$, onde se destacam os membros superiores do poder público e de organizações privadas é de 18 vezes. Do mesmo modo, no que tange à posição na ocupação, os trabalhadores domésticos (com ou sem carteira assinada) situam-se no extremo inferior $(-1,56)$ e os empregadores no oposto $(28,86)$. Esta diferença de rendimentos conforme a posição na ocupação representa uma variação de 27 vezes.

Para o censo de 2000 foram substituídos os anos de estudo pelo tipo de curso realizado (57 tipos nos níveis de graduação, mestrado e doutorado, além daqueles sem curso superior) e mantido o grupo ocupacional e a posição na ocupação como as demais variáveis independentes, com o montante de rendimentos como variável dependente. Assim, é possível examinar as variações relacionadas às diferenças relativamente ao tipo de titulação escolar e não apenas quanto aos anos de estudo. Ao incluir todas essas variáveis relativamente ao montante de rendimentos conforme o tipo de titulação constata-se que, de longe, aqueles sem um curso superior têm o menor rendimento $(3,56$, com um valor constante para o modelo de 23,88$) .{ }^{15}$ Isso equivale a 27 vezes menos que a faixa de maior rendimento, onde se destacam aqueles com mestrado ou doutorado em medicina $(96,25)$. No entanto, mesmo quando incluídos apenas aqueles com curso superior, numa comparação formalmente horizontal, não são observadas variações muito significativas, sendo que o extremo inferior, onde se destacam os profissionais com graduação em medicina veterinária $(8,30)$. Em relação aos grupos ocupacionais e de posição na ocupação, neste modelo não se observa alterações significativas quando se substitui os anos de estudo pelo tipo de curso concluído. Relativamente aos agrupamentos ocupacionais, no extremo superior, situam-se os membros do poder público ou de organizações de empresas $(2,74)$, seguidos de perto pelos profissionais das ciências e das artes $(1,93)$. No extremo oposto, desta- 
cam-se categorias como a dos trabalhadores agropecuários, florestais e da caça e pesca $(19,84)$, de serviços e do comércio em lojas e mercados e demais agrupamentos de trabalhadores. Quanto à posição na ocupação, como nos demais modelos, no extremo superior, destacam-se os empregadores $(27,97)$ e no extremo oposto os trabalhadores domésticos - com ou sem carteira assinada $(-2,81)$. Portanto, também para esta base de dados, os retornos dos investimentos em educação dependem diretamente da posição social, tomada pela ocupação.

Como já mencionado, as Pnad's de 1996 e de 1988 foram incluídas particularmente porque contêm algumas informações relativas às origens sociais, especialmente a ocupação e o grau de escolarização dos pais. Portanto, nesses casos, a ocupação e o grau de escolarização dos pais, além da ocupação e posição na ocupação (com o montante dos rendimentos como variável dependente) foram incluídas no modelo de regressão linear. Para a Pnad 1996, a variação no montante de rendimentos (sobre o total de horas trabalhadas) relativamente aos anos de estudo é de 44,69 (quinze anos de estudo ou mais) a 0,41 (dois anos de estudo). Porém, o que mais se ressalta é a não linearidade nas relações entre a quantidade de anos de estudo e de rendimentos, como também encontrado para as demais bases de dados. Da mesma forma, a associação mais significativa entre os anos de estudo e o montante de rendimentos ocorre somente nos grupos com mais de onze anos de estudo. No que tange à posição na ocupação, o escopo das variações é de 22,16 para os empregadores a valores negativos para os trabalhadores domésticos - com ou sem carteira assinada $(-2,52)$ e para os empregados sem carteira assinada $(-2,50)$.

Observa-se um padrão semelhante quanto à ocupação, embora com menor amplitude de variação. Novamente, no extremo superior situam-se os empregadores $(10,78)$, seguidos de longe pelos profissionais com funções técnicas, científicas, artísticas e assemelhados $(4,49)$. No extremo oposto, com valores negativos, destacam-se categorias como as ocupações na agropecuária, produção e extração vegetal, mineral e animal $(-2,47)$, em funções burocráticas e de escritório $(-0,08)$, dentre outras. Para a ocupação do pai, os resultados são semelhantes aos obtidos para a própria ocupação. No extremo superior, destacam-se agrupamentos de ocupação do pai como as funções técnicas, científicas, artísticas e assemelhadas $(17,08)$, seguidos pelas funções administrativas, comércio e atividades auxiliares $(6,89)$, de transporte, comunicação e de prestação de serviços $(5,01)$, e ocupações mal definidas. Nesse caso também, no extremo inferior, destacam-se trabalhadores na agricultura ou na extração vegetal, mineral e animal (2,03), seguidos pelos da indústria de transformação. Por fim, quanto ao montante de rendimentos e grau de escolarização do pai, no extremo superior situam-se os profissionais com pai com curso superior, mestrado ou doutorado $(19,15)$, seguidos de longe pelos com ensino médio ou curso superior incompleto e com curso elementar completo. No extremo inferior, destacam-se os que nunca 
frequentaram escola ou que têm menos de um ano de estudo $(1,46)$ e trabalhadores com curso elementar incompleto.

Embora os resultados não possam ser expostos em detalhes, para a Pnad de 1988 também é constatado um alto grau de associação entre as variáveis (tabela não incluída no anexo), incluindo as relacionadas com as origens sociais ( $R$ de 0,514 e $R^{2}$ de $0,264)$; com a ocupação ( $R$ de 0,554 e $R^{2}$ de 0,307 ); com a posição na ocupação ( $R$ de 0,557 e $R^{2}$ de 0,311); ocupação do pai ( $R$ de 0,551 e $R^{2}$ de 0,338); e grau de escolarização do pai ( $R$ de 0,598 e $R^{2}$ de 0,357). A exceção nesse grau de associação são as variáveis relativas à posição na ocupação, enquanto as com correlação mais intensa são as relativas aos anos de estudo, à própria ocupação e à ocupação e grau de escolarização do pai.

\section{Considerações finais}

Em geral, os anos de estudo têm efeitos positivos no montante de rendimentos. Isso já foi confirmado por diversas pesquisas, que serviram como ponto de partida para este trabalho. No entanto, o presente trabalho não trata dos retornos positivos da escolarização, ocupa-se mais especificamente das condições sociais de realização e de valorização da titulação escolar. A grande importância atribuída à existência e à quantidade de retornos dos investimentos em educação pode ser atribuída à importância dos estudos econômicos sobre o tema. Além disso, este tipo de estudo geralmente é baseado em preocupações prescritivas imediatas. Para os estudos de sociologia, a superação desse caráter normativo e prescritivo desse tipo de estudo pressupõe e requer certo grau de autonomia.

A maioria das pesquisas sobre este tema sugere uma não linearidade entre os anos de estudo e o montante de rendimentos. Em geral, essa não linearidade é atribuída ao efeito diploma ou o "efeito pele de carneiro". No entanto, este trabalho sustenta a hipótese de que, nas condições estudadas, o efeito diploma representa apenas uma parte mínima das diferenças nos rendimentos. As razões para as diferenças nos retornos da escolarização devem ser buscadas na diversidade de condições e significados dos investimentos educacionais de acordo com a posição social e sua multidimensionalidade. Em síntese, o problema das relações entre escolarização e rendimentos varia de acordo com a respectiva posição social e, portanto, com os significados e usos sociais dos títulos e graus escolares. Por outro lado, o enfrentamento dessa questão sofre com as limitações das categorias estatísticas, cuja formulação não necessariamente está centrada nos problemas de análise de posição social.

Em todas as bases de dados, muitas das faixas de anos de estudo apresentam uma forte diminuição nos rendimentos em comparação com a faixa imediatamente an- 
terior. Além disso, constata-se que as relações positivas entre os anos de estudo e o montante de rendimentos são mais significativas apenas para as faixas mais elevadas e particularmente para aquela no extremo superior. Esta distribuição variada dos efeitos positivos da escolarização sobre o montante de rendimentos, quando confrontada com a ocupação, é aproximadamente homóloga à estrutura de posições sociais.

A hipótese principal deste trabalho é a de que o valor da escolarização e da titulação escolar depende de condições sociais concretas e multidimensionais, para além do mercado educacional e de trabalho tomados de modo abstrato e universalizado. 0 presente trabalho enfoca as condições e a posição na ocupação, conjuntamente com a quantidade de educação e o montante de rendimentos.

Esta análise inclui um maior número de variáveis do que geralmente é utilizada neste tipo de estudo e especifica as relações entre a escolarização e o montante de rendimentos para cada categoria ocupacional. Assim, foi possível examinar as relações entre os anos de estudo e rendimentos para cada base de dados e explorar as relações diferenciadas entre as divisões de trabalho e títulos educacionais frente ao destino ocupacional.

Evidentemente, muitos problemas centrais ainda não foram resolvidos, tanto pelas limitações metodológicas como pela base de dados disponíveis. De qualquer modo, a principal lição que fica é que este tipo de estudo não se limita a reafirmar ou negar as conclusões de economistas apoiados na teoria do capital humano. Por outro lado, também não pode se restringir a contestar os limites das abordagens mais usuais, seja de economistas centrados na teoria do capital humano ou de perspectivas envoltas em problemas normativos ou práticos dos agentes imersos no universo escolar. 0 requerimento mais importante para a análise sociológica é a formulação de um problema exclusivo relacionado às condições sociais que geram o valor da educação, em termos positivos ou negativos. O uso de efeitos positivos da educação como fundamento de posições político-ideológicas deve ser tomado como questão relevante no estudo da sociologia e não como contraponto.

Abstract: This article presents the results of a study on the relationship between income level, education and other indicators of social position in Brazil. Research has attributed the non-linear relationship between the number of years of education and income level to the effect of a diploma alone, but this study hypothesizes that, although the diploma effect is almost always present to some degree, it has a minimal effect on differences in incomes. The increase in income is negative for several categories of the number of years of education, and the positive effect is only significant at the higher ranges, particularly the group with the highest number of years. Along with education, other indicators, such as those linked to occupation, have similar degrees of association with income level.

Keywords: return on educational investments; individual effects of education; occupacional categories and social position; education, occupation and income. 


\section{Referências}

Alba-Ramirez, A.; Segundo, M. J. S. The returns to education in Spain. Economics of Education Review, v. 14, n. 2, 1995: 155-166.

AltonsI, J. G.; DunN, T. A. The effects of family characteristics on the return to education. The Review of Economics and Statistics, v. 78, n. 4, Nov. 1996: 692-704.

BARBosa, M. L. DE O. Desigualdade e desempenho: uma introdução à sociologia da escola brasileira. Belo Horizonte: Argumentum, 2009.

BAUDELOT et alii. Les effets de l'éducation. Rapport à l'intention du Programme incitatif de recherche en éducation et formation (Piref). Paris: École Normale Supérieure, 2004.

BECKER, Gary S. Human capital and the personal distribution of income. Ann Arbor: University of Michigan Press, 1967.

Bergman, M. M.; JOYE, D. Comparing social stratification schemata: CAMSIS, CSP-CH, Goldthorpe, ISCO-88, Treiman, and Wright. Cambridge Studies in Social Research, n. 10, 2005; SSRG Publications. <http://www.ppsis.cam.ac.uk/srg/workingpapers/ CS10StratificationSchemata2.pdf>.

BJÖRKLUND, A.; KJELLSTRÖM, C. Estimating the return to investments in education: how useful is the standard Mincer equation? Economics of Education Review, n. 21, 2000 : 195-210.

BOURDIEU, P.; BOLTANSKI, L. Le titre et le poste: rapports entre le système de production et le système de reproduction. Actes de la Recherche en Sciences Sociales, n. 2, 1975 : 95-106.

BouRdieu, P.; SAINT MARTIN, M. DE. Agrégration et segregation. Le champ des grandes écoles et le champ du pouvoir. Actes de la Recherche en Sciences Sociales, n. 69, 1987: $2-50$.

BourdieU, P.; Christin, R. La construction du marché. Le champ administratif et la production de la politique du logement, Actes de la Recherche en Sciences Sociales, n. 81/82, Mar. 1990: 65-85.

BourdieU, P. Homo academicus. Paris: Les Éditions de Minuit, 1984.

_ . La distinction. Critique sociale du jugement. Paris: Les Éditions de Minuit, 1979.

— . La noblesse d'État: grandes écoles et esprit de corps. Paris: Les Éditions de Minuit, 1989. 
BRAND, J. E. Heterogeneous effects of higher education on civic participation: a research note. California Center for Population Research, Sep. 2009.

BREEN, R. \& LUIJKX, R. Social mobility in europe between 1970 and 2000. In: BREEN, R. (Ed.). Social mobility in Europe. Oxford: Oxford University Press, 2004, p. 37-75.

BREEN, R. (Ed.). Social mobility in Europe. Oxford: Oxford University Press, 2004.

BROWN, D. K. The social sources of educational credentialism: status cultures, labor markets, and organizations. Sociology of Education, Extra Issue, 2001, p. 19-34.

ChaUVEL, L. Le retour des classes sociales? Revue de l'Observatoire Français des Conjonctures Economiques (OFCE), v. 4, n. 79, 2001, p. 315-359.

Chauvel, L. et alii. Enjeux et usages des catégories socioprofessionelles; traditions nationales, comparaisons internationals et standardization européenne. Presses de Sciences Po, v. 1, n. 45-46, 2002, p. 157-185.

ColuINS, R. The credential society: an historical sociology of education and stratification. London: Academic Press, 1979.

CORADINI, O. L. Titulação escolar, condição de "elite" e posição social. Revista Brasileira de Educação, v. 15, n. 43, Jan./Abr. 2010, p. 35-97.

- The divergences between Bourdieu's and Coleman's notions of social capital and theirepistemological limits. Social Science Information, v. 49, Nov. 2010b, p. 563583.

DEE, T. S. Are there civic returns to education? Cambridge: National Bureau of Economic Research, 2003.

ERIKSON, R.; GOLDTHORPE, J. H. The constant flux: a study of class mobility in industrial societies. Oxford: Clarendon, 1992.

FERNANDES, R.; NARITA, R. D. T. Instrução superior e mercado de trabalho no brasil. Economia Aplicada, v. 5, n. 1, 2001, p. 6-32.

GoldthoRPE, J. H. Causation, statistics, and sociology. European Sociological Review, v. 17, n. 1, 2001, p. 1-20.

HAIR JR., J. F. et alii. Análise multivariada de dados. 6. ed. Porto Alegre: Bookman, 2009.

InStituto Brasileiro de Geografia e Estatística (IBGE). Censo demográfico 2000 agregado de setores censitários dos resultados do universo. Documentação dos Arquivos de Dados. Rio de Janeiro: IBGE, 2002. <http://www.aprogeosp.org.br/dicsetoribge.pdf>. 
- Censo demográfico de 2000. Microdados. 3. ed. Rio de Janeiro: IBGE, 2003. (CD-ROM).

. Censo Demográfico de 2000. Microdados. 3. ed. Rio de Janeiro: IBGE, 2003. (Compact Disc).

. Classificação de ocupações para pesquisas domiciliares - COD; principais diferenças entre a COD e a CBO domiciliar. Rio de Janeiro: IBGE, 2010. <http://www. ibge.gov.br/home/estatistica/indicadores/sipd/oitavo_forum/COD.pdf>.

—. Pesquisa nacional por amostra de domicílios 1988. Microdados. Rio de Janeiro: IBGE, 2006. (Compact Disc).

Pesquisa nacional por amostra de domicílios 1996. Microdados. Rio de Janeiro: IBGE, 2004. (Compact Disc).

. Pesquisa nacional por amostra de domicílios 2006. Microdados. Rio de Janeiro: IBGE, 2007. (Compact Disc).

JACKSON, M.; GoldThoRPE, J. H.; Mills, C. Education, employers and class mobility. Paper prepared for the Oxford meeting of the International Sociological Association, Research Committee 28, Social Stratification and Mobility, 2002. <http://www.nuffield. ox.ac.uk/rc28/Papers/Jackson.pdf>.

JAEGER, D. A., PAGE, M. E. Degreees matter: new evidnces on sheepskin in the returns to education. The Review of Economics and Statistics, v. 78, n. 4, 1996, p. 733-740.

LAM, D.; SCHOENI, R. F. Effects of family background on earnings and returns to schooling: evidence from Brazil. Journal of Political Economy, v. 101, n. 4, 1993a, p. 710-740.

_. Family ties and labor markets in the Unites States and Brazil. Labor and Population Program. Working Paper Series 93-25, 1993b.

LAM, D. Age, experience, and schooling: decomposing earnings inequality in the United States and Brazil. Social Inquiry, v. 62, n. 2, Spring 1992, p. 221-245.

LANGoni, C. As causas do crescimento econômico do Brasil. 3. ed. Rio de Janeiro: Apec, 1974.

LEBARON, F. L'analyse géométrique des données dans un programme de recherche sociologique: les cas de la sociologie de Bourdieu. Revue Modulad, n. 62, 2010, p. 102-109.

LIU, J. T.; HAMMITT, J. K.; LIN, C. J. Family background and returns to schooling in Taiwan. Economic of Education Review, v. 19, 2000, p. 113-125. 
LONG, M. C. Changes in the returns to educational and college quality. Economics of Education Review, 2009. <http://www.sciencedirect.com/science/article>.

MERLLIÉ, D. Les catégories socio-professionelles et les conditions de leur mise en œuvre. Actes de La Recherche en Sciences Sociales, v. 50, Nov. 1983, p. 4-47.

MINCER, Jacob B. Schooling, experience and earnings. New York: National Bureau of Economic Research, 1974.

MofFITT, R. Estimationg marginal returns to higher education in the UK. Cambridge: National Bureau of Economic Research, 2007.

MÜLLER, W. CASMIN educational classification. <http://www.nuff.ox.ac.uk/Users/Yaish/NPSM/Casmin\%20 Educ.pdf>.

NeRI, M. C. O Paradoxo da evasão e as motivações dos sem escola. In Veloso, F. et alii (Orgs.). Educação básica no Brasil; construindo o país do futuro. Rio de Janeiro: Elsevier, 2009.

PATRINOS, H. A. Socioeconomic background, schooling, experience, ability and monetary reward in Greece. Economics of Education Review, v. 14, n. 1, 1995, p. 85-91

PSACHAROPOULOS, G. Returns to education: a further international update and implications. Journal of Human Resources, v. 20, 1985, p. 583-604.

- Economics of education: a 50-year anniversary recap. Athens. Athens University, 2008.

Psacharopoulos, G.; Patrinos, H. A. Returns to investment in education: a global update. World Development, v. 22, n. 9. Sept. 1994, p. 1.325-1.343.

ROUANET, H. et alii. Régression et analyse géométrique des données: réflexions et suggestions. Mathematiques et Sciences Humaines. 40ème année, n. 160, 2002, p. 1345.

. The geometric analysis of questionnaires: the lesson of bourdieu's la distinction. Bulletin of Sociological Methodology, n. 65, Jan. 2000, p. 5-18.

Veloso, F. et alii (Orgs.). Educação básica no Brasil; construindo o país do futuro. Rio de Janeiro: Elsevier, 2009.

ZARCA, B. Les patrons dans la statistique officielle française. Politix, n. 23, 1993, p. 44-65.

ZeLIZER, V. Repenser le marché: La construction sociale du "marché aux bebés" aux États-Unis, 1870-1930. Actes de la Recherche em Sciences Sociales, n. 94, Sept. 1992, p. 3-26. 


\section{Anexos}

TABELA 1

REGRESSÃO LINEAR (PNAD 2009)

\begin{tabular}{|c|c|c|c|c|c|}
\hline & $\begin{array}{l}\text { Unstandardized } \\
\text { coefficients }\end{array}$ & Std. error & $\begin{array}{l}\text { Standardized } \\
\text { coefficients }\end{array}$ & $\mathrm{t}$ & P \\
\hline (constant) & 71.51 & 1.410 & & 50.7 & 0.000 \\
\hline 1 ano de estudo & -0.09 & 2.307 & 0.000 & 0.0 & 0.968 \\
\hline 2 anos de estudo & 0.45 & 2.460 & 0.000 & 0.2 & 0.855 \\
\hline 3 anos de estudo & 6.22 & 1.819 & 0.006 & 3.4 & 0.001 \\
\hline 4 anos de estudo & 8.24 & 1.361 & 0.012 & 6.1 & 0.000 \\
\hline 5 anos de estudo & 2.70 & 1.749 & 0.003 & 1.5 & 0.123 \\
\hline 6 anos de estudo & 20.64 & 1.914 & 0.019 & 10.8 & 0.000 \\
\hline 7 anos de estudo & 10.68 & 1.852 & 0.010 & 5.8 & 0.000 \\
\hline 8 anos de estudo & 1.84 & 1.367 & 0.003 & 1.3 & 0.178 \\
\hline 9 anos de estudo & 15.35 & 1.667 & 0.018 & 9.2 & 0.000 \\
\hline 10 anos de estudo & 14.82 & 1.911 & 0.014 & 7.8 & 0.000 \\
\hline 11 anos de estudo & 24.81 & 1.138 & 0.066 & 21.8 & 0.000 \\
\hline 12 anos de estudo & 51.72 & 2.263 & 0.039 & 22.9 & 0.000 \\
\hline 13 anos de estudo & 6.20 & 2.292 & 0.005 & 2.7 & 0.007 \\
\hline 14 anos de estudo & 48.15 & 1.701 & 0.058 & 28.3 & 0.000 \\
\hline 15 anos de estudo ou mais & 71.80 & 1.309 & 0.261 & 54.9 & 0.000 \\
\hline Dirigentes em geral & 19.73 & 0.964 & 0.038 & 20.5 & 0.000 \\
\hline $\begin{array}{l}\text { Técnicos de nível médio (e professores sem curso } \\
\text { superior) }\end{array}$ & -60.52 & 0.930 & -0.126 & -65.1 & 0.000 \\
\hline Trabalhadores em serviços administrativos & -60.35 & 1.015 & -0.128 & -59.5 & 0.000 \\
\hline Trabalhadores dos serviços & -57.52 & 1.150 & -0.139 & -50.0 & 0.000 \\
\hline Trabalhadores (e produtores) agrícolas & -58.16 & 1.213 & -0.138 & -48.0 & 0.000 \\
\hline $\begin{array}{l}\text { Trabalhadores na produção de bens e serviços } \\
\text { e de reparos e manutenção }\end{array}$ & -58.45 & 1.198 & -0.109 & -48.8 & 0.000 \\
\hline $\begin{array}{l}\text { Membros das forças armadas e auxiliares em } \\
\text { ocupações mal definidas }\end{array}$ & 4.53 & 2.638 & 0.003 & 1.7 & 0.086 \\
\hline Empregado com carteira assinada & -13.13 & 0.704 & -0.040 & -18.6 & 0.000 \\
\hline Funcionário público estatutário e militar & -17.44 & 0.757 & -0.051 & -23.0 & 0.000 \\
\hline Empregado sem carteira assinada & -6.93 & 0.708 & -0.020 & -9.8 & 0.000 \\
\hline Trabalhador doméstico, com ou sem carteira assinada & -7.37 & 1.449 & -0.010 & -5.1 & 0.000 \\
\hline Empregador & 114.65 & 0.934 & 0.252 & 122.8 & 0.000 \\
\hline Não remunerados & -14.92 & 2.366 & -0.011 & -6.3 & 0.000 \\
\hline
\end{tabular}

Dependent variable: rendimento mensal de todas as fontes para pessoas de 10 anos ou mais de idade sobre o total de horas semanais trabalhadas.

Coeficiente de determinação $\left(R^{2}\right)=0.279$. 
TABELA 2

REGRESSÃO LINEAR (PNAD 2006)

\begin{tabular}{|c|c|c|c|c|c|}
\hline & $\begin{array}{l}\text { Unstandardized } \\
\text { coefficients }\end{array}$ & Std. error & $\begin{array}{l}\text { Standardized } \\
\text { coefficients }\end{array}$ & $\mathrm{t}$ & $P$ \\
\hline (Constant) & -2.41 & 0.019 & & -128.7 & 0.000 \\
\hline 1 ano de estudo & 0.11 & 0.035 & 0.000 & 3.1 & 0.019 \\
\hline 2 anos de estudo & 0.12 & 0.029 & 0.000 & 4.2 & 0.002 \\
\hline 3 anos de estudo & 0.58 & 0.025 & 0.002 & 23.3 & 0.000 \\
\hline 4 anos de estudo & 1.50 & 0.022 & 0.008 & 69.5 & 0.000 \\
\hline 5 anos de estudo & 1.11 & 0.024 & 0.005 & 46.2 & 0.000 \\
\hline 6 anos de estudo & 0.41 & 0.027 & 0.002 & 15.3 & 0.000 \\
\hline 7 anos de estudo & 1.06 & 0.026 & 0.004 & 40.7 & 0.000 \\
\hline 8 anos de estudo & 1.68 & 0.023 & 0.009 & 72.8 & 0.000 \\
\hline 9 anos de estudo & 0.95 & 0.030 & 0.003 & 31.9 & 0.000 \\
\hline 10 anos de estudo & 1.23 & 0.030 & 0.004 & 41.7 & 0.000 \\
\hline 11 anos de estudo & 4.58 & 0.021 & 0.032 & 216.7 & 0.000 \\
\hline 12 anos de estudo & 9.04 & 0.041 & 0.020 & 222.0 & 0.000 \\
\hline 13 anos de estudo & 11.34 & 0.045 & 0.022 & 250.3 & 0.000 \\
\hline 14 anos de estudo & 13.17 & 0.045 & 0.026 & 289.8 & 0.000 \\
\hline 15 anos de estudo ou mais & 43.74 & 0.030 & 0.182 & 1437.2 & 0.000 \\
\hline Dirigentes em geral & -6.93 & 0.071 & -0.020 & -97.3 & 0.000 \\
\hline Profissionais das ciências e das artes & -1.40 & 0.066 & -0.005 & -21.1 & 0.000 \\
\hline $\begin{array}{l}\text { Técnicos de nível médio (e professores leigos e de } \\
\text { nível médio) }\end{array}$ & -12.12 & 0.066 & -0.045 & -184.4 & 0.000 \\
\hline Trabalhadores de serviços administrativos & -23.26 & 0.065 & -0.092 & -357.1 & 0.000 \\
\hline Trabalhadores dos serviços & -24.52 & 0.064 & -0.169 & -383.9 & 0.000 \\
\hline Trabalhadores (e produtores) agrícolas & -25.64 & 0.065 & -0.148 & -391.8 & 0.000 \\
\hline $\begin{array}{l}\text { Trabalhadores da produção industrial e de serviços } \\
\text { de reparos e manutenção industrial }\end{array}$ & -23.52 & 0.064 & -0.145 & -367.8 & 0.000 \\
\hline Ocupações mal definidas e militares em geral & -12.56 & 0.094 & -0.015 & -133.4 & 0.000 \\
\hline Empregado com carteira assinada & 38.81 & 0.063 & 0.273 & 612.5 & 0.000 \\
\hline Funcionário público estatutário e militar & 43.71 & 0.068 & 0.154 & 640.6 & 0.000 \\
\hline Empregado sem carteira assinada & 35.26 & 0.065 & 0.196 & 546.2 & 0.000 \\
\hline Empregado doméstico, com ou sem carteira assinada & 37.52 & 0.068 & 0.142 & 555.4 & 0.000 \\
\hline Por conta própria & 45.77 & 0.065 & 0.274 & 705.3 & 0.000 \\
\hline Empregador & 76.97 & 0.072 & 0.221 & 1066.9 & 0.000 \\
\hline $\begin{array}{l}\text { Trabalhador na produção ou construção para o } \\
\text { próprio consumo ou uso }\end{array}$ & 57.51 & 0.071 & 0.173 & 814.4 & 0.000 \\
\hline Não remunerado & 30.98 & 0.068 & 0.106 & 453.5 & 0.000 \\
\hline
\end{tabular}

Coeficiente de determinação $\left(R^{2}\right)=0.129$. 
TABELA 3

REGRESSÃO LINEAR (PNAD 1996)

\begin{tabular}{|c|c|c|c|c|c|}
\hline & $\begin{array}{l}\text { Unstandardized } \\
\text { coefficients }\end{array}$ & Std. error & $\begin{array}{l}\text { Standardized } \\
\text { coefficients }\end{array}$ & $\mathrm{t}$ & $P$ \\
\hline (Constant) & 3.48 & 0.152 & & 22.9 & 0.000 \\
\hline 1 ano de estudo & 0.51 & 0.018 & 0.003 & 29.0 & 0.000 \\
\hline 2 anos de estudo & 0.79 & 0.014 & 0.007 & 56.7 & 0.000 \\
\hline 3 anos de estudo & 1.25 & 0.012 & 0.014 & 101.2 & 0.000 \\
\hline 4 anos de estudo & 2.55 & 0.010 & 0.038 & 245.0 & 0.000 \\
\hline 5 anos de estudo & 1.60 & 0.013 & 0.018 & 128.2 & 0.000 \\
\hline 6 anos de estudo & 1.77 & 0.015 & 0.015 & 117.5 & 0.000 \\
\hline 7 anos de estudo & 2.34 & 0.015 & 0.021 & 156.9 & 0.000 \\
\hline 8 anos de estudo & 3.83 & 0.012 & 0.048 & 316.1 & 0.000 \\
\hline 9 anos de estudo & 3.01 & 0.019 & 0.019 & 156.6 & 0.000 \\
\hline 10 anos de estudo & 4.34 & 0.018 & 0.030 & 240.6 & 0.000 \\
\hline 11 anos de estudo & 7.46 & 0.012 & 0.107 & 618.4 & 0.000 \\
\hline 12 anos de estudo & 11.02 & 0.025 & 0.053 & 444.4 & 0.000 \\
\hline 13 anos de estudo & 14.52 & 0.029 & 0.059 & 505.0 & 0.000 \\
\hline 14 anos de estudo & 16.89 & 0.026 & 0.077 & 640.9 & 0.000 \\
\hline 15 anos de estudo ou mais & 34.05 & 0.016 & 0.351 & 2124.6 & 0.000 \\
\hline Funcionários públicos estatutários e militares & -1.57 & 0.011 & -0.017 & -138.0 & 0.000 \\
\hline Empregado sem carteira assinada & -1.37 & 0.008 & -0.023 & -174.0 & 0.000 \\
\hline Trabalhador doméstico, com ou sem carteira assinada & -1.26 & 0.013 & -0.015 & -93.6 & 0.000 \\
\hline Por conta própria & 3.52 & 0.008 & 0.063 & 458.7 & 0.000 \\
\hline Empregadores & 13.09 & 0.018 & 0.107 & 732.0 & 0.000 \\
\hline $\begin{array}{l}\text { Trabalhadores na produção ou construção para o } \\
\text { próprio consumo ou uso }\end{array}$ & 20.07 & 0.023 & 0.101 & 854.6 & 0.000 \\
\hline Não remunerado & 5.12 & 0.031 & 0.018 & 162.9 & 0.000 \\
\hline $\begin{array}{l}\text { Empregadores e administradores em organizações } \\
\text { públicas e privadas }\end{array}$ & 9.65 & 0.152 & 0.101 & 63.4 & 0.000 \\
\hline Funções burocráticas e de escritório & 0.09 & 0.152 & 0.001 & 0.5 & 0.550 \\
\hline $\begin{array}{l}\text { Funções técnicas, científicas, artísticas e } \\
\text { assemelhadas }\end{array}$ & 3.97 & 0.152 & 0.047 & 26.1 & 0.000 \\
\hline $\begin{array}{l}\text { Agropecuária e produção e extração vegetal, mineral } \\
\text { e animal }\end{array}$ & -2.18 & 0.152 & -0.033 & -14.3 & 0.000 \\
\hline Industria de transformação e construção civil & 0.41 & 0.152 & 0.007 & 2.7 & 0.006 \\
\hline $\begin{array}{l}\text { Comércio e atividades auxiliares e transporte e } \\
\text { comunicação }\end{array}$ & 1.30 & 0.152 & 0.020 & 8.6 & 0.000 \\
\hline Prestação de serviços & -0.12 & 0.152 & -0.002 & -0.8 & 0.400 \\
\hline $\begin{array}{l}\text { Outras e ocupações mal definidas (inclusive da } \\
\text { segurança) }\end{array}$ & 0.91 & 0.152 & 0.010 & 6.0 & 0.000 \\
\hline $\begin{array}{l}\text { Pai com ocupação técnica, científica, artística e } \\
\text { assemelhadas }\end{array}$ & 6.61 & 0.027 & 0.032 & 242.7 & 0.000 \\
\hline
\end{tabular}




\begin{tabular}{|c|c|c|c|c|c|}
\hline Pai com funções administrativas & 5.17 & 0.014 & 0.047 & 362.4 & 0.000 \\
\hline $\begin{array}{l}\text { Pai com ocupação na agricultura e produção e } \\
\text { extração vegetal, mineral e animal }\end{array}$ & 0.28 & 0.009 & 0.005 & 31.8 & 0.000 \\
\hline Pai com ocupação na indústria de transformação & 1.50 & 0.012 & 0.017 & 130.1 & 0.000 \\
\hline Pai com ocupação no comércio e atividades auxiliares & 3.91 & 0.015 & 0.031 & 253.5 & 0.000 \\
\hline Pai com ocupação nos transportes e comunicação & 2.12 & 0.017 & 0.015 & 123.2 & 0.000 \\
\hline Pai com ocupação na prestação de serviços & 2.55 & 0.035 & 0.008 & 72.8 & 0.000 \\
\hline Pai com ocupação mal definida & 2.57 & 0.015 & 0.022 & 177.6 & 0.000 \\
\hline Pai nunca frequentou escola ou $1^{\text {a }}$ série do $1^{\circ}$ grau & 1.46 & 0.009 & 0.025 & 159.4 & 0.000 \\
\hline Pai com 1aa à $3^{a}$ série do 10 grau & 2.49 & 0.010 & 0.038 & 258.1 & 0.000 \\
\hline $\begin{array}{l}\text { Pai com elementar completo ou } 1 \text { ạ à } 3 \text { ạ série do } 1 \text { 으 } \\
\text { grau }\end{array}$ & 5.03 & 0.011 & 0.065 & 458.5 & 0.000 \\
\hline 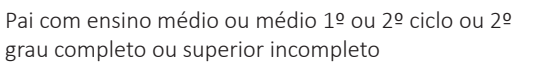 & 7.77 & 0.014 & 0.073 & 545.7 & 0.000 \\
\hline $\begin{array}{l}\text { Pai com curso superior completo ou mestrado ou } \\
\text { doutorado }\end{array}$ & 19.15 & 0.028 & 0.093 & 689.7 & 0.000 \\
\hline
\end{tabular}

Coeficiente de determinação $\left(R^{2}\right)=0.288$. 